\title{
A study of the distribution of color Doppler flows in the superficial digital flexor tendon of young Thoroughbreds during their training periods
}

\author{
Takashi HATAZOE ${ }^{1}$, Yoshiro ENDO ${ }^{2}$, Yohei IWAMOTO ${ }^{2}$, Kenji KOROSUE$^{2}$, \\ Taisuke KURODA ${ }^{3}$, Saemi INOUE ${ }^{4}$, Daiki MURATA ${ }^{4}$, Seiji HOBO ${ }^{4}$ and Kazuhiro MISUMI ${ }^{4}$ * \\ ${ }^{1}$ Kyusyu Stallion Station, The Japan Bloodhorse Breeders' association, Kagoshima 899-8313, Japan \\ 2Japan Racing Association Miyazaki Training Farm, Miyazaki 880-0036, Japan \\ 3Japan Racing Association Equine Research Institute, Tochigi 320-0856, Japan \\ ${ }^{4}$ Joint Faculty of Veterinary Medicine, Kagoshima University, Kagoshima 890-0065, Japan
}

\begin{abstract}
Aim of this study was to evaluate the relationships of exercise and tendon injury with Doppler flows appearing in the superficial digital flexor tendon (SDFT) of young Thoroughbreds during training periods. The forelimb SDFTs of 24 one- to two-year-old Thoroughbreds clinically free of any orthopaedic disorders were evaluated using greyscale (GS) and color Doppler (CD) images during two training periods between December 2013 to April 2015. Twelve horses per year were examined in December, February, and April in training periods that began in September and ended in April. The SDFT was evaluated in 3 longitudinal images of equal lengths (labelled 1, 2, 3 in order from proximal to distal), and 6 transversal images separated by equal lengths (labelled 1A, 1B, 2A, 2B, $3 A$ and $3 B$ in order from proximal to distal) of the metacarpus using both $G S$ and $C D$. The running (canter and gallop) distance for 1 month before the date of the ultrasonographic examinations was increased in December, February, and April in both of the two training periods. CD flows defined as rhythmically blinking or pulsatory colored signals were found in 56 of 864 (6.4\%) transversal $C D$ images, in 28,12, 13, and 3 images of $1 \mathrm{~A}, 1 \mathrm{~B}, 2 \mathrm{~A}$ and $2 B$, respectively, and in 7, 14, and 35 images captured in December, February, and April, respectively. There were no longitudinal or transversal GS images indicating injury in the SDFTs in either of the two training periods. The increase of $C D$ flows in the proximal regions of the SDFT are possibly related to the increase of the running distance during the training periods of the one- to two-year-old Thoroughbreds. Because no injury was diagnosed in the SDFTs by GS images during the training periods, the increase of CD flows in the proximal parts of SDFT is not necessarily predictive of tendon injury in the near future during the training period of young Thoroughbreds.
\end{abstract}

Key words: blood flow, color Doppler, tendon, Thoroughbred, training

\author{
J. Equine Sci. \\ Vol. 26, No. 4 \\ pp. 99-104, 2015
}

Ultrasonography is the gold standard for diagnosing injuries of the equine superficial digital flexor tendon (SDFT), and has been improved with the aim of clarifying the time course of the healing process [23]. In general,

Received: June 30, 2015

Accepted: August 21, 2015

*Corresponding author. e-mail: kaz_msm@vet.kagoshima-u.ac.jp (C)2015 Japanese Society of Equine Science

This is an open-access article distributed under the terms of the Creative Commons Attribution Non-Commercial No Derivatives (bync-nd) License $<$ http://creativecommons.org/licenses/by-nc-nd/3.0/>. grey-scale (GS) transversal and longitudinal images of the acute phase of the injured tendon are defined by the lower echo (hypoechoic or anechoic) areas that are indicative of the haemorrhage and early inflammation associated with the injury of the tendon bundles [24]. Grey level lesions slowly return to normal echogenicity, as the injured area is refilled with granulation or scar tissues over the course of time [24]. The diagnosis of the time course of primary injury and the completion of healing is critical. We can predict the prognosis based on the quantitative analysis of the primary injury in the macroscopic tendon bundles using GS 
ultrasonography [7], but it is also desirable that microscopic injuries prior to a macroscopic injury can be detected using GS images. If the resolution of GS ultrasonography could be improved to diagnose the injuries of microscopic tendon bundles, we might become able to predict the occurrence of macroscopic injury.

Interest in color Doppler (CD) or power Doppler ultrasonography has recently spread to the determination of micro blood flows in the locomotive system. In human rheumatoid arthritis, increased Doppler flow signals in the proliferative synovium facilitates the differentiation between active and inactive synovitis [2]. In horses with chronic tendinopathy, CD ultrasonography is useful as a diagnostic tool for intratendinous hyperaemia and short-term outcomes, including the closure of intratendinous vessels without exacerbation of symptoms after the injection of therapeutic agents [5]. An experimental study in the field of sports medicine found that CD examination of equine symptomatic SDFT can demonstrate neovascularization in areas with structural changes in the tendon [13]. Previously, we reported that histopathology suggests the number of blood vessels increases in the tendon bundles of Thoroughbred racehorses with a history of SDFT rupture [16], and speculated that semi-quantitative determination of blood flows in the equine tendon by CD ultrasonography might offer a new method for differentiating between active and inactive inflammation in the tendon associated with the injuries, as well as in deciding the time course of injured tendon bundles. Long distance runners with current or healed Achilles tendon complaints display an increase in hypoechoic lesions and neovascularizations, and also neovascularization is often found in the tendons of asymptomatic runners, as determined by modern power Doppler equipment [8]. Another recent paper concluded that power Doppler ultrasonography of intratendinous microvessels in the Achilles tendons of healthy runners seems to be a prognostically relevant factor related to the manifestation of symptomatic Achilles tendinopathy [9]. Thus, evaluation of blood flow in equine SDFT by CD, as demonstrated by human studies of the Achilles tendon, might be useful in the early detection of predisposition to injury, and might lead to the prevention of injury and a favorable prognosis. The aim of this study was to evaluate the relationships of exercise and tendon injury with CD flows appearing in the SDFT of young Thoroughbreds which had no injury before their training periods.

\section{Materials and Methods}

The animals were 24 one- to two-year-old Thoroughbreds (twelve males, twelve females) clinically free of any orthopaedic disorders and history. Prior to a breaking and training period that begins in September and ends in April
Table 1. Changes of running distance for 1 month before the dates of the ultrasonographic examination in December, February, and April

\begin{tabular}{lcc}
\hline & $2013(\mathrm{~km} /$ month $)$ & $2014(\mathrm{~km} / \mathrm{month})$ \\
\hline December & $9.6 \pm 6.3$ & $9.8 \pm 5.2$ \\
February & $47.7 \pm 1.8$ & $34.0 \pm 9.6$ \\
April & $54.0 \pm 18.1$ & $45.6 \pm 7.6$ \\
\hline
\end{tabular}

Running was performed at a canter and a gallop.

every year, twelve horses (six males, six females) were selected as subjects in the first study from December 2013 to April 2014. The other twelve horses were used in the second study from December 2014 to April 2015. The running (that is at a canter and a gallop) distances for 1 month before the dates of the ultrasonographic examination are presented in Table 1.

\section{Ultrasonographic examination}

The horses' SDFTs were ultrasonographically scanned on the same dates in December, February, and April. Before the examination, the horses had been kept in pasture for at least $3 \mathrm{hr}$ following their daily exercise. The horses were retained in a treatment stall, and then sedated with medetomidine ( $2 \mathrm{mg} /$ head intravenous injection). After completely clipping the palmar aspect from the proximal to the distal metacarpus, a linear array transducer $(50 \mathrm{~mm}$ of effective aperture length) with a broadband frequency between 5 and $12 \mathrm{MHz}$ was directly placed onto the skin with abundant gel. Using a mobile ultrasound system (iU22, Philips Medical Systems Corporation, Tokyo, Japan), three longitudinal (three equal lengths of the labelled 1 to 3 in order from proximal to distal metacarpus) and six transversal (separated by equal distance along the labelled $1 \mathrm{~A}, 1 \mathrm{~B}, 2 \mathrm{~A}, 2 \mathrm{~B}$, $3 \mathrm{~A}$ and $3 \mathrm{~B}$ in order from proximal to distal, Fig. 1) images from the proximal end (bottom of the accessory carpal bone) to the distal end (top of the proximal sesamoid bone) of the SDFT were scanned. The maximum depth of the image was $3.5 \mathrm{~cm}$, and the depth of focus was adjusted to the SDFT. Both GS and CD images were recorded for 15 and $30 \mathrm{sec}$ at frame rates of $45 \mathrm{~Hz}$ and 6 to $11 \mathrm{~Hz}$, respectively. All images of tendons were recorded under weight-bearing conditions.

The macroscopic injury of tendon bundles was diagnosed using the GS images. Blood flows in the tendon bundles were visualized in the longitudinal and transversal $C D$ images, in which the region of interest was set and the gain setting was similar for all tendons, just below the noise level (77-85\% of maximal gain). The maximum color activity of transversal CD images (Fig. 2) was recorded and graded, as previously reported: grade 1, tiny to small color activities that were rhythmically blinking at a site, but for which flow rates were not measurable by pulsed Doppler; grade 

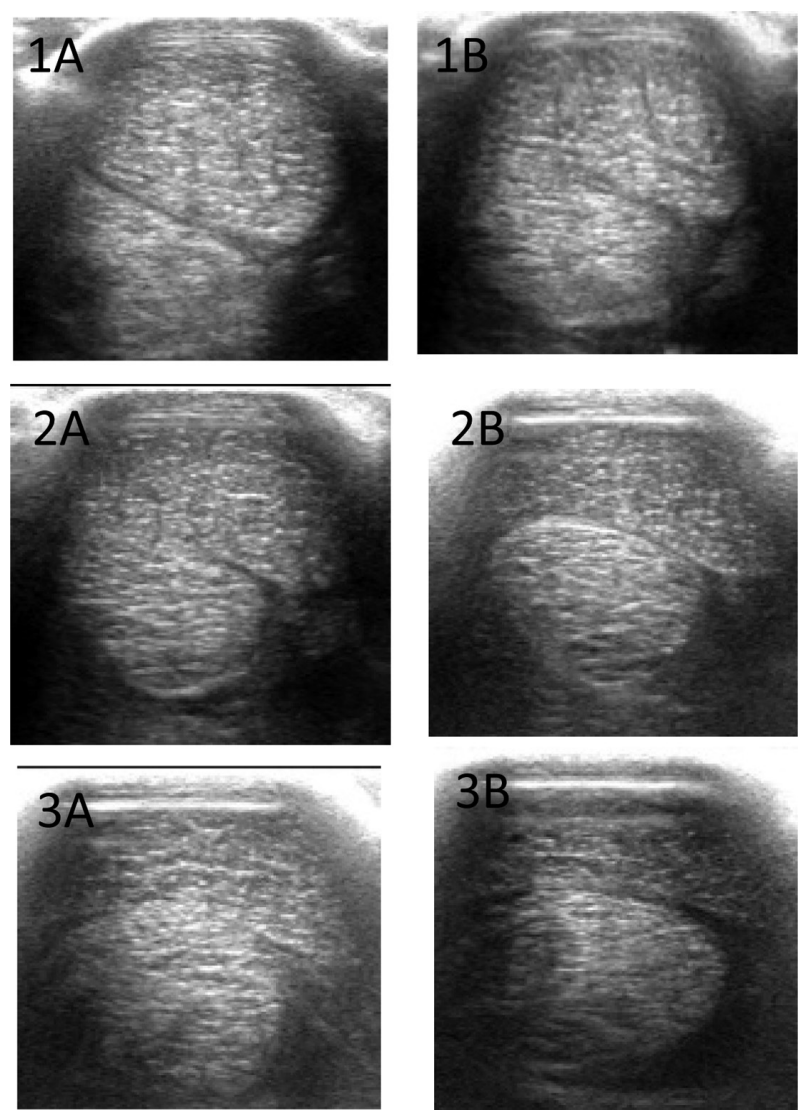

Fig. 1. Transversal (1A-3B) GS images. After completely clipping the palmar aspect of the metacarpus, a linear array transducer was directly placed on the skin with abundant gel. The rounded SDFT was clearly outlined in the 1A, 1B and 2A images; however, the lateral and medial margins could not be visualized in the flattened SDFT of the $2 \mathrm{~B}, 3 \mathrm{~A}$ and $3 \mathrm{~B}$ images.

2, unequivocal color activities that were pulsatile dots and for which flow rates were measured by pulsed Doppler; and grade 3, unequivocal linear color activities appearing as blood streams in a regular direction due to periodic changes in color [16]. The longitudinal CD scan was inferior to the transversal one in detecting and recording the small color activities of grade 1 and 2, therefore we used only the transversal images for the $\mathrm{CD}$ data analysis.

\section{Results}

The running distance for 1 month before the date of the ultrasonographic examination was increased in the order of December, February, and April in both of the two training periods. As the transversal GS images were obtained using a linear array transducer that was directly placed onto the skin with abundant gels and not attached to a coupler, the rounded SDFT was clearly outlined in $1 \mathrm{~A}, 1 \mathrm{~B}$, and $2 \mathrm{~A}$

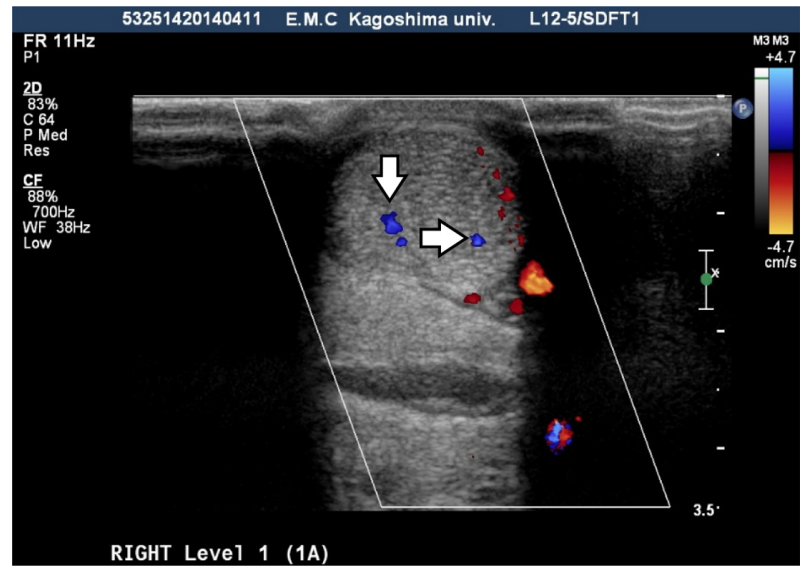

Fig. 2. A transversal CD image of the SDFT. The positive signals of CD flow are grade 1 (indicated by white arrows), small color activities that were fixed and rhythmically blinking.

images, however the lateral and medial margins could not be visualized in the flattened SDFT of $2 \mathrm{~B}, 3 \mathrm{~A}$ and $3 \mathrm{~B}$ (Fig. 1). There were no longitudinal or transversal GS images indicating injury in the SDFTs in either of the two training periods.

Of 864 ( 6 images $\times 2$ forelimbs $\times 24$ horses $\times 3$ examinations) transversal CD images, 56 images (6.4\%) showed the CD flows in SDFT bundles (Table 2), which were categorized as rhythmically blinking (grade 1, 32 images, as presented in Fig. 2) or pulsatory coloring signals (grade 2, 23 images). The $\mathrm{CD}$ flows were unevenly distributed at $1 \mathrm{~A}, 1 \mathrm{~B}, 2 \mathrm{~A}$ and $2 \mathrm{~B}$, and were more frequently detected in April than in either December or February (Table 3). There were 7, 8 and 15 horses showing CD flows in December, February and April, respectively.

\section{Discussion}

A normal tendon is hypovascular, and angiogenesis or increased vascularity are associated with an injured tendon for much of the healing process. Within the first $24 \mathrm{hr}$ after injury (inflammatory phase), inflammatory cells are recruited to the injured site, and vasoactive and chemotactic factors are associated with an increase in vascular permeability and the initiation of angiogenesis [17, 22]. Within a few days, tenocytes gradually migrate to the injury site, proliferate, and synthesize type III collagen (proliferative phase) $[19,22]$. After approximately six weeks, the repair tissue changes from cellular to fibrous (remodelling phase). The fibrous tissue gradually changes to scar-like tendon tissue over the course of one year (maturation stage) [10, $22]$, and the vascularity finally declines in the latter half of this stage $[1,22]$. Therefore, we hypothesised that the 
Table 2. Among 864 transversal CD images, 56 images (6.4\%) showed positive CD flows in SDFT bundles

\begin{tabular}{|c|c|c|c|c|c|c|c|c|c|c|c|c|c|c|}
\hline \multicolumn{15}{|c|}{ December 2013-April 2014} \\
\hline Horse & Region & Dec & Feb & Apr & Horse & Region & Dec & Feb & Apr & Horse & Region & Dec & $\mathrm{Feb}$ & Apr \\
\hline \multirow{7}{*}{ A } & $1 \mathrm{~A}$ & & & & \multirow{7}{*}{ E } & $1 \mathrm{~A}$ & & R-G1 & R-G1 & \multirow{7}{*}{ I } & $1 \mathrm{~A}$ & & & \\
\hline & 1B & R-G1 & & R-G1 & & $1 \mathrm{~B}$ & & R-G1 & R-G1 & & 1B & & & \\
\hline & $2 \mathrm{~A}$ & & & R-G2 & & $2 \mathrm{~A}$ & & & L-G1 & & $2 \mathrm{~A}$ & & & \\
\hline & & & & & & & & & R-G1 & & & & & \\
\hline & 2B & & & & & $2 \mathrm{~B}$ & & & R-G2 & & 2B & & & \\
\hline & $3 \mathrm{~A}$ & & & & & $3 \mathrm{~A}$ & & & & & $3 \mathrm{~A}$ & & & \\
\hline & 3B & & & & & 3B & & & & & 3B & & & \\
\hline \multirow{8}{*}{ B } & $1 \mathrm{~A}$ & & & R-G1 & \multirow{8}{*}{$\mathrm{F}$} & $1 \mathrm{~A}$ & & L-G1 & L-G2 & \multirow{8}{*}{$\mathrm{J}$} & $1 \mathrm{~A}$ & & & R-G1 \\
\hline & & & & & & & & R-G1 & & & & & & \\
\hline & 1B & & & L-G2 & & 1B & L-G1 & R-G1 & & & $1 \mathrm{~B}$ & & & R-G1 \\
\hline & $2 \mathrm{~A}$ & & & L-G2 & & $2 \mathrm{~A}$ & & & R-G1 & & $2 \mathrm{~A}$ & & & \\
\hline & & & & R-G2 & & & & & & & & & & \\
\hline & $2 \mathrm{~B}$ & & & R-G1 & & $2 \mathrm{~B}$ & & & R-G1 & & $2 \mathrm{~B}$ & & & \\
\hline & $3 \mathrm{~A}$ & & & & & $3 \mathrm{~A}$ & & & & & $3 \mathrm{~A}$ & & & \\
\hline & $3 \mathrm{~B}$ & & & & & 3B & & & & & 3B & & & \\
\hline \multirow{7}{*}{$\mathrm{C}$} & $1 \mathrm{~A}$ & & & L-G2 & \multirow{7}{*}{ G } & $1 \mathrm{~A}$ & L-G1 & L-G1 & \multirow{7}{*}{ L-G1 } & \multirow{7}{*}{$\mathrm{K}$} & $1 \mathrm{~A}$ & & & \\
\hline & & & & & & & & R-G2 & & & & & & \\
\hline & 1B & & & & & $1 \mathrm{~B}$ & & & & & $1 \mathrm{~B}$ & & & \\
\hline & $2 \mathrm{~A}$ & & & & & $2 \mathrm{~A}$ & & & & & $2 \mathrm{~A}$ & & & \\
\hline & $2 \mathrm{~B}$ & & & & & $2 \mathrm{~B}$ & & & & & $2 \mathrm{~B}$ & & & \\
\hline & $3 \mathrm{~A}$ & & & & & $3 \mathrm{~A}$ & & & & & $3 \mathrm{~A}$ & & & \\
\hline & $3 \mathrm{~B}$ & & & & & $3 \mathrm{~B}$ & & & & & $3 \mathrm{~B}$ & & & \\
\hline \multirow{6}{*}{ D } & $1 \mathrm{~A}$ & & & L-G1 & \multirow{6}{*}{$\mathrm{H}$} & $1 \mathrm{~A}$ & R-G1 & & R-G1 & \multirow{6}{*}{$\mathrm{L}$} & $1 \mathrm{~A}$ & R-G2 & R-G1 & $\begin{array}{l}\text { L-G2 } \\
\text { R-G1 }\end{array}$ \\
\hline & 1B & & & & & 1B & & & R-G1 & & 1B & & & \\
\hline & $2 \mathrm{~A}$ & L-G1 & & L-G2 & & $2 \mathrm{~A}$ & & & R-G2 & & $2 \mathrm{~A}$ & & & \\
\hline & $2 \mathrm{~B}$ & & & & & $2 \mathrm{~B}$ & & & & & $2 \mathrm{~B}$ & & & \\
\hline & $3 \mathrm{~A}$ & & & & & $3 \mathrm{~A}$ & & & & & $3 \mathrm{~A}$ & & & \\
\hline & $3 \mathrm{~B}$ & & & & & $3 \mathrm{~B}$ & & & & & $3 \mathrm{~B}$ & & & \\
\hline & & & & & & ecember & $014-\mathrm{A}$ & cil 2015 & & & & & & \\
\hline Horse & Region & Dec & Feb & Apr & Horse & Region & Dec & Feb & Apr & Horse & Region & Dec & Feb & Apr \\
\hline & $1 \mathrm{~A}$ & & & L-G2 & & $1 \mathrm{~A}$ & & R-G2 & R-G2 & & $1 \mathrm{~A}$ & & & \\
\hline & 1B & & & & & 1B & & & & & $1 \mathrm{~B}$ & & & \\
\hline M & $2 \mathrm{~A}$ & & & & Q & $2 \mathrm{~A}$ & & & & U & $2 \mathrm{~A}$ & & & \\
\hline & $2 \mathrm{~B}$ & & & & & $2 \mathrm{~B}$ & & & & & $2 \mathrm{~B}$ & & & \\
\hline & $3 \mathrm{~A}$ & & & & & $3 \mathrm{~A}$ & & & & & $3 \mathrm{~A}$ & & & \\
\hline & $3 \mathrm{~B}$ & & & & & $3 \mathrm{~B}$ & & & & & $3 \mathrm{~B}$ & & & \\
\hline & $1 \mathrm{~A}$ & & L-G1 & & & $1 \mathrm{~A}$ & & R-G1 & & & $1 \mathrm{~A}$ & & & \\
\hline & $1 \mathrm{~B}$ & & & & & $1 \mathrm{~B}$ & & R-G2 & & & $1 \mathrm{~B}$ & & & \\
\hline & $2 \mathrm{~A}$ & & & & & $2 \mathrm{~A}$ & & & R-G2 & & $2 \mathrm{~A}$ & & & \\
\hline $\mathrm{N}$ & $2 \mathrm{~B}$ & & & & $\mathrm{R}$ & $2 \mathrm{~B}$ & & & & $V$ & $2 \mathrm{~B}$ & & & \\
\hline & $3 \mathrm{~A}$ & & & & & $3 \mathrm{~A}$ & & & & & $3 \mathrm{~A}$ & & & \\
\hline & $3 \mathrm{~B}$ & & & & & 3B & & & & & $3 \mathrm{~B}$ & & & \\
\hline & $1 \mathrm{~A}$ & R-G2 & & L-G2 & & $1 \mathrm{~A}$ & & & & & $1 \mathrm{~A}$ & & & \\
\hline & $1 \mathrm{~B}$ & & & L-G2 & & $1 \mathrm{~B}$ & & & & & $1 \mathrm{~B}$ & & & \\
\hline & $2 \mathrm{~A}$ & & & R-G2 & & $2 \mathrm{~A}$ & & & & & $2 \mathrm{~A}$ & & & \\
\hline $\mathrm{O}$ & $2 \mathrm{~B}$ & & & & S & $2 \mathrm{~B}$ & & & & W & $2 \mathrm{~B}$ & & & \\
\hline & $3 \mathrm{~A}$ & & & & & $3 \mathrm{~A}$ & & & & & $3 \mathrm{~A}$ & & & \\
\hline & $3 \mathrm{~B}$ & & & & & $3 \mathrm{~B}$ & & & & & $3 \mathrm{~B}$ & & & \\
\hline & $1 \mathrm{~A}$ & & & & & $1 \mathrm{~A}$ & & & & & $1 \mathrm{~A}$ & & L-G2 & L-G1 \\
\hline & $1 \mathrm{~B}$ & & & & & $1 \mathrm{~B}$ & & & & & $1 \mathrm{~B}$ & & R-G2 & \\
\hline & $2 \mathrm{~A}$ & & & & & $2 \mathrm{~A}$ & & & & & $2 \mathrm{~A}$ & & & \\
\hline $\mathrm{P}$ & $2 \mathrm{~B}$ & & & & $\mathrm{~T}$ & $2 \mathrm{~B}$ & & & & X & $2 \mathrm{~B}$ & & & \\
\hline & $3 \mathrm{~A}$ & & & & & $3 \mathrm{~A}$ & & & & & $3 \mathrm{~A}$ & & & \\
\hline & $3 \mathrm{~B}$ & & & & & $3 \mathrm{~B}$ & & & & & $3 \mathrm{~B}$ & & & \\
\hline
\end{tabular}

L (or R)-G1 (or 2) are abbreviations for Left forelimb (or Right forelimb)-Grade 1 (or 2). 
Table 3. The distribution of transversal CD images showing positive CD flows in SDFT bundles

\begin{tabular}{lrcrcccc}
\hline & $1 \mathrm{~A}$ & $1 \mathrm{~B}$ & $2 \mathrm{~A}$ & $2 \mathrm{~B}$ & $3 \mathrm{~A}$ & $3 \mathrm{~B}$ & Total \\
\hline December & 4 & 2 & 1 & 0 & 0 & 0 & 7 \\
February & 10 & 4 & 0 & 0 & 0 & 0 & 14 \\
April & 14 & 6 & 12 & 3 & 0 & 0 & 35 \\
\hline Total & 28 & 12 & 13 & 3 & 0 & 0 & 56 \\
\hline
\end{tabular}

blood flows would also increase in equine SDFT from a few days to six weeks after the injury, and that they might be indicative of tendon injury and the subsequent healing process. However, in this study of one- to two-year-old horses, no macroscopic injury was found in the 56 transversal GS images in which positive signals of blood flow were seen within SDFT bundles. Some of the positive flow signals disappeared and/or then reappeared during the study period. Therefore, we speculate that the positive signals of blood flow observed in this study might be due to transient increases of blood flows in the inherent vessels in response to hypoxia [3] and/or hyperthermia [11, 20, 25] of tendon tissue which were related to the increased exercise (the increased mechanical behaviour of the tendon), rather than increased vascularization associated with macroscopic injury of tendon bundles. Based on the observance of increased Doppler flow in Achilles tendons that was associated with weekly badminton hours and badminton years, it was suggested that Doppler flow may be a response to mechanical load on the tendon [15]. Since Doppler activity increased in human Achilles tendons after running exercise performed by both non-symptomatic subjects and symptomatic subjects in a rehabilitation program, it was proposed that all tendons of both healthy and diseased subjects, have a certain amount of vascularization, which may be manifested on demand up to a certain level [4]. Considering our result in reference to these human studies, it is possible that the blood flows observed in the SDFT of the one- to two-yearold Thoroughbreds were response to the increases in the intensity and distance of the running exercise during the training period.

The main sources of blood supply are: the intrinsic systems at the myotendinous and osteotendinous junctions, and the extrinsic system through the paratenon or the synovial sheath. The ratio of the blood supply from the intrinsic systems to that from the extrinsic system varies in the different parts of the tendon. For example, the central third, which could be a zone of hypovascularity, receives $35 \%$ of its blood supply from the extrinsic system in the rabitt Achilles tendon [14, 18]. An equine study reported that the blood supply of the normal SDFT is primarily intratendinous rather than paratendinous as previously thought
[12]. In this study, the $\mathrm{CD}$ flows mainly increased in $1 \mathrm{~A}(28$ images), 1B (12 images), and 2A (13 images), which are proximal parts of the SDFT. This result could be suggestive of increased blood supply from the intrinsic systems at the myotendinous junction. At the myotendinous junction, perimysial vessels from the muscle continue between the fascicles of the tendon [21], and extend to the proximal third of the human Achilles tendon [6, 22]. Although we have no data regarding the blood vessel distribution from the superficial digital flexor myotendinous junction to the proximal third of metacarpal SDFT in horses, this result might be explained as the perimysial blood supply to the proximal third physiologically increasing in response to the increases in the running distance of the clinically healthy horses.

In conclusion, the increase of intratendinous blood flows in the proximal parts of the SDFT could be responses to the increase in exercise intensity as the training advanced. Because no longitudinal or transversal GS image indicating macroscopic injury of the SDFT were found in either of the two training periods, increase of $\mathrm{CD}$ flows in the proximal parts of the SDFT are not necessarily predictive of tendon injury in the near future in the training period of young Thoroughbreds.

\section{Acknowledgments}

The authors thank Dr. Akiyama K. for the technical assistance provided to this study.

\section{References}

1. Amiel, D., Akeson, W.H., Harwood, F.L., and Frank, C.B. 1983. Stress deprivation effect on metabolic turnover of the medial collateral ligament collagen. A comparison between nine- and 12-week immobilization. Clin. Orthop. Relat. Res. 265-270. [Medline]

2. Backhaus, M. 2009. Ultrasound and structural changes in inflammatory arthritis: synovitis and tenosynovitis. Ann. N. Y. Acad. Sci. 1154: 139-151. [Medline] [CrossRef]

3. Birch, H.L., Rutter, G.A., and Goodship, A.E. 1997. Oxidative energy metabolism in equine tendon cells. Res. Vet. Sci. 62: 93-97. [Medline] [CrossRef]

4. Boesen, M.I., Koenig, M.J., Torp-Pedersen, S., Bliddal, H., and Langberg, H. 2006. Tendinopathy and Doppler activity: the vascular response of the Achilles tendon to exercise. Scand. J. Med. Sci. Sports 16: 463-469. [Medline] [CrossRef]

5. Boesen, M.I., Nanni, S., Langberg, H., Boesen, M., FalkRonne, J., Bliddal, H., and Torp-Pedersen, S. 2007. Colour doppler ultrasonography and sclerosing therapy in diagnosis and treatment of tendinopathy in horses-a research model for human medicine. Knee Surg. Sports Traumatol. 
Arthrosc. 15: 935-939. [Medline] [CrossRef]

6. Carr, A.J., and Norris, S.H. 1989. The blood supply of the calcaneal tendon. J. Bone Joint Surg. Br. 71: 100-101. [Medline]

7. Genovese, R.L., Rantanen, N.W., Simpson, B.S., and Simpson, D.M. 1990. Clinical experience with quantitative analysis of superficial digital flexor tendon injuries in Thoroughbred and Standardbred racehorses. Vet. Clin. North Am. Equine Pract. 6: 129-145. [Medline]

8. Hirschmüller, A., Frey, V., Deibert, P., Konstantinidis, L., Mayer, F., Südkamp, N., and Helwig, P. 2010. [Achilles tendon power Doppler sonography in 953 long distance runners-a cross sectional study]. Ultraschall Med. 31: 387-393. [Medline]

9. Hirschmüller, A., Frey, V., Konstantinidis, L., Baur, H., Dickhuth, H.H., Südkamp, N.P., and Helwig, P. 2012. Prognostic value of Achilles tendon Doppler sonography in asymptomatic runners. Med. Sci. Sports Exerc. 44: 199-205. [Medline] [CrossRef]

10. Hooley, C.J., and Cohen, R.E. 1979. A model for the creep behaviour of tendon. Int. J. Biol. Macromol. 1: 123-132. [CrossRef]

11. Ker, R.F. 1981. Dynamic tensile properties of the plantaris tendon of sheep (Ovis aries). J. Exp. Biol. 93: 283-302. [Medline]

12. Kraus-Hansen, A.E., Fackelman, G.E., Becker, C., Williams, R.M., and Pipers, F.S. 1992. Preliminary studies on the vascular anatomy of the equine superficial digital flexor tendon. Equine Vet. J. 24: 46-51. [Medline] [CrossRef]

13. Kristoffersen, M., Ohberg, L., Johnston, C., and Alfredson, H. 2005. Neovascularisation in chronic tendon injuries detected with colour Doppler ultrasound in horse and man: implications for research and treatment. Knee Surg. Sports Traumatol. Arthrosc. 13: 505-508. [Medline] [CrossRef]

14. Kvist, M., Józsa, L., and Järvinen, M. 1992. Vascular changes in the ruptured Achilles tendon and paratenon. Int. Orthop. 16: 377-382. [Medline] [CrossRef]

15. Malliaras, P., Richards, P.J., Garau, G., and Maffulli, N. 2008. Achilles tendon Doppler flow may be associated with mechanical loading among active athletes. Am. J. Sports Med. 36: 2210-2215. [Medline] [CrossRef]

16. Murata, D., Misumi, K., and Fujiki, M. 2012. A prelimi- nary study of diagnostic color Doppler ultrasonography in equine superficial digital flexor tendonitis. J. Vet. Med. Sci. 74: 1639-1642. [Medline] [CrossRef]

17. Murphy, P.G., Loitz, B.J., Frank, C.B., and Hart, D.A. 1994. Influence of exogenous growth factors on the synthesis and secretion of collagen types I and III by explants of normal and healing rabbit ligaments. Biochem. Cell Biol. 72: 403-409. [Medline] [CrossRef]

18. Naito, M., and Ogata, K. 1983. The blood supply of the tendon with a paratenon. An experimental study using hydrogen washout technique. Hand 15: 9-14. [Medline] [CrossRef]

19. Oakes, B.W. 2003. Tissue healing and repair: tendons and ligaments. pp. 56-98. In: Rehabilitation of Sports Injuries: Scientific Basis (Frontera, W.R. ed.), Blackwell Science, Boston.

20. Riemersma, D.J., and Schamhardt, H.C. 1985. In vitro mechanical properties of equine tendons in relation to cross-sectional area and collagen content. Res. Vet. Sci. 39: 263-270. [Medline]

21. Riley, G.P., Harrall, R.L., Cawston, T.E., Hazleman, B.L., and Mackie, E.J. 1996. Tenascin-C and human tendon degeneration. Am. J. Pathol. 149: 933-943. [Medline]

22. Sharma, P., and Maffulli, N. 2005. Tendon injury and tendinopathy: healing and repair. J. Bone Joint Surg. Am. 87: 187-202. [Medline] [CrossRef]

23. van Schie, H.T., Bakker, E.M., Cherdchutham, W., Jonker, A.M., van de Lest, C.H., and van Weeren, P.R. 2009. Monitoring of the repair process of surgically created lesions in equine superficial digital flexor tendons by use of computerized ultrasonography. Am. J. Vet. Res. 70: 37-48. [Medline] [CrossRef]

24. van Schie, H.T., Bakker, E.M., Jonker, A.M., and van Weeren, P.R. 2001. Efficacy of computerized discrimination between structure-related and non-structure-related echoes in ultrasonographic images for the quantitative evaluation of the structural integrity of superficial digital flexor tendons in horses. Am. J. Vet. Res. 62: 1159-1166. [Medline] [CrossRef]

25. Wilson, A.M., and Goodship, A.E. 1994. Exercise-induced hyperthermia as a possible mechanism for tendon degeneration. J. Biomech. 27: 899-905. [Medline] [CrossRef] 